\title{
LETTERS
}

\section{Compliance packaging: Be aware of the hidden cost}

I agree with Law and colleagues ${ }^{1}$ that the cost of therapy is an important factor that may result in suboptimal adherence to medical treatment. Other barriers to adherence include treatment for asymptomatic conditions or risk factors, complex medical regimens, adverse effects, drugdrug interactions and poor understanding on the part of the individual patient.

To improve adherence to therapy, various modalities have been used in clinical practice, including compliance packaging (also known as blister packs), which have some benefits, ${ }^{2}$ such as ensuring the integrity of medications by improving shelf life, providing a barrier against tampering, and preventing accidental or intentional overdose. However, a major limitation is the increased cost of therapy if the blister packs are filled by pharmacies at 2- to 4-week intervals (as opposed to every 3 months when medications are prescribed in containers). Each time the new blister pack is given to the patient, a full dispensing fee is charged either to the patient or to the insurer. The dispensing cost associated with refilling the blister packs is a major cost factor in comparison to the cost of the actual medication, especially for common conditions for which the medications are often generic. For example, the cost of a single 90-day prescription of metformin is $\$ 10.99$ for the cost of the drug plus the dispensing fee (which is usually about $\$ 10$ ). But if the same medication is filled monthly, the cost is more than doubled $(\$ 4.10 \times 3=\$ 12.54$ for the cost of the drug + the dispensing fee 3 times over). If the same prescription is filled every 14 days, then the cost is 3.5 times higher for 6 fewer days of supply. This additional cost from the dispensing fee becomes increasingly prohibitive as the number of therapeutic agents increases.

When writing prescriptions, physicians should consider not only the actual cost of medications, but also the dispensing fees charged to the patient. It is preferable to give patients who are stable on therapy at least a 3-month supply to curtail the dispensing costs, especially when patients are taking many medications. Pharmacies should supply the prescribed duration of therapy, whether the medications are dispensed in containers or in compliance packaging, and must follow the Ontario Drug Interchangeability and Dispensing Fee Act, which states, "The medications used in the compliance aid are to be dispensed for the entire prescribed quantity, unless otherwise indicated by the patient or prescriber."3 Pharmacists should be transparent with patients about the indirect increased cumulative cost of prescriptions when the duration of refills is shortened.

\section{Malvinder S. Parmar MB MS}

Consultant physician, Northern Ontario School of Medicine, Sudbury, Ont.

Cite as: CMAJ 2019 November 25;191: E1313. doi: $10.1503 / \mathrm{cmaj} .73349$

\section{References}

1. Law MR, Cheng L, Dhalla IA, et al. The effect of cost on adherence to prescription medications in Canada. CMAJ 2012;184:297-302.

2. Lee JK, Grace KA, Taylor AJ. Effect of a pharmacy care program on medication adherence and persistence, blood pressure, and low-density lipoprotein cholesterol: a randomized controlled trial. JAMA 2006;296:2563-71.

3. Drug Interchangeability and Dispensing Fee Act, R.S.O. 1990, c. P.23 Section 9.1. Available: www. ontario.ca/laws/statute/90p23\#BK9 (accessed 2019 July 22)

Competing interests: None declared. 